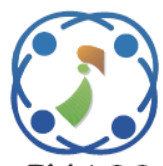

\title{
Recommendation of Diet to Anaemia Patient on the Basis of Nutrients Using AHP and Fuzzy TOPSIS Approach
}

\author{
Mahendra Pratap Singh ${ }^{1} \quad$ Sanjay Kumar Dubey ${ }^{*}$ \\ ${ }^{1}$ Amity University Uttar Pradesh, Sec-125, Noida, India \\ *Corresponding author's Email:skdubey1@amity.edu
}

\begin{abstract}
Anaemia is a serious health condition caused primarily by deficiency of iron in the body. In India cases of anaemia are on an alarmingly high rate affecting pregnant women, men and children alike. Malnutrition has been identified as the primary cause of iron deficiency. The treatment of anaemia can be accomplished by adhering to a stringent diet plan containing all the critical nutrients in the right amount. This makes it a complex process to pick the most relevant diet plan among all the available ones. Our objective here pertains to determining the best diet plan for anaemia patient and to procure this we are employing Analytic Hierarchy Process (AHP) in the proposed paper. Diet recommendation for anaemia patient using AHP is relatively new, making this work as unique. The results obtained show the best diet among the available ones that must be recommended to an anaemia patient. This diet contains all the meals that must be consumed at breakfast, lunch and dinner by an anaemia patient. The proposed work is further validated using Fuzzy Technique for Order of Preference by Similarity to Ideal Solution (TOPSIS). The results obtained after validation are exactly the same as determined using AHP.
\end{abstract}

Keywords: Anaemia, Diet, Nutrients, AHP, Fuzzy TOPSIS

\section{Introduction}

Anaemia, caused mainly by lack of iron in the body results in decrease in the capacity of red blood cells (RBCs) to carry oxygen in the blood. This results in symptoms such as tiredness, fatigue, shortness of breath, pale skin and yellowish eyes. Anaemia can also be caused by decrease in production of RBCs in the body or by excessive destruction of RBCs, resulting in poor health and inability to carry out daily activities in life. Iron deficiency anaemia causes rapid decrease in the productivity of workforce causing huge economic loss. It affects pregnant women and children severely. According to a report published in Nutrition in 2014, anaemia caused around 50 percent of maternal deaths in India. Pregnant women suffering from anaemia have a greater chance of foetal deaths and abnormalities in the new born babies. In young children suffering from Anaemia, it hinders their ability to participate in sports and other extra-curricular activities. They are weak and inactive in comparison to their healthy peers. They also lack in understanding of basic subjects such as languages, elementary mathematics etc. This drastically affects their growth and personality development at an early age. Among adult men, anaemia causes several issues such as inability to focus on work, lack of strength in manual work which leads to loss of employment and poverty. This seriously affects their economic stability as well as mental state. Another horror associated with anaemia is that it provokes many other serious diseases and illnesses which can induce long term problems for the body. This widespread prevalence of Anaemia is due to lack of nutritional diet, poor living condition and inability to afford medical services due to financial reasons [1-3].

The research work on recommendation of diet has been done by several techniques and approaches in previous works. In order to meet the need to provide efficient service to people of Sudan, an expert system for providing diet recommendation to diabetes patient is developed. It employs acquisition 
of knowledge, analysis of the acquired knowledge, formalization of it and finally designing the system and bringing about the formal implementation of the proposed expert system [4]. A consultation system for recommending diets for patients suffering from chronic kidney diseases has been developed. It takes into account the patient's current state of health, the stage of his illness, the food consumed by the patient, the amount of daily activities he endorses and the exempted key nutrients. It is developed using web ontology language along with sematic web rule language [5]. However, this paper fails to provide for the specific meals that must be administered to a patient during the day.

Type 2 fuzzy ontology along with application of knowledge representation for personal diabetic diet recommendation is used for diet recommendation to diabetic patients in Taiwan. The domain experts decide what diet is to be provided in what measure to the patients. The patients need to provide the food consumed by them as input to develop the knowledge base. This lead to development of an intelligent diet recommendation system which helps in daily planning of meal for diabetes patients [6]. The servings for the amount and type of meal has been provided for but the main drawback is the inability to provide with specific food items that contain the prescribed nutrients and their servings. Rigors of everyday work life cause ill maintained diet, unhealthy eating habits and lack of attention to personal needs. This may lead to development of serious illnesses. However all this can be prevented by eating a proper and balance diet. Recipe ontology is used to recommend diet to users based on their preferences and health conditions [7]. The only problem associated with it was the absence of personalized food recommendation denoting the diet plan a person must follow. Children in India suffer the most from malnutrition. ID3 algorithm is used for providing menu for recommending diet to children based on factors such as likeness, availability, climatic conditions and any special preferences. The proposed framework consists of two levels: Level 0, which contains basic information about the user and Level 1, which contains information about the demographics of the user. This is a great work but lacks in one major aspect which is to provide for the cases when a child suffers from a particular disease and the type of meal he should be given because at that point some of the factors such as likeness, climatic conditions and preferences might not work [8].

Fuzzy logic and ontology are used for recommending diet based on Ayurveda and prakriti. The concept of prakriti is exploited here to determine the diet that a person with a certain prakriti needs to adhere to. Every person has different prakriti depending upon his time of birth, thus every person should have a different diet plan; one that meets the needs of that particular individual. The factors such as inherited disease or birth abnormalities have not been considered in this work. This work is not useful for an ill person as no such parameter for any disease has been taken into account. Also the nutrients and their impact on diet has not been clearly studied upon [9]. An approach for developing an expert system for diet recommendation based on ripple down rule is proposed to provide for personal diet recommendation for a health record management application [10]. Data mining techniques are used for recommending diet to cancer patient so that he recovers quickly. The techniques used together are case based reasoning, rule based reasoning and genetic algorithm. First technique isolates the diet plans from the existing ones. Second technique removes irrelevant cases from the system. The third technique gives the personalized diet recommendation to the actual patient. This consists of the food and dishes that are to be included in the $\operatorname{diet}[11]$.

As it can be seen form the works mentioned above, the diet recommendation approaches are more focused on the external factors such as demand, recipe, likeness, availability, prakriti etc. rather than the internal factors such as the nutrients themselves that must be present in the diet. The nutrients according to our work should be the most important factor for deciding the diet rather than the other external factors. In order to provide the nutrients their due importance in the diet, the presented paper employs Analytic Hierarchy Process (AHP) for recommendation of diet. This method has numerous other advantages over the previously proposed techniques for diet recommendation. Firstly, the emphasis in the proposed work is more on the essential nutrients that must be present in the diet. A diet containing these nutrients would automatically be more beneficial to the patient. Secondly, by employing AHP in this paper, an exact diet plan has been provided for, which contains all the meals that are to be consumed throughout the day. This maintains the balance of the nutrients in the body at all times. Thirdly, in the previous works the biasness in the user's feedback was not accounted for. This could result in the inconsistent data thus making all of the work unreliable. AHP checks for this consistency by determining the consistency ratio, the value of which shows the consistency in the user's or expert's feedback. Fourthly, since AHP is 
conventionally used for selecting the best alternative which contains all the critical factors, the proposed paper here harnesses this very feature to provide for the best diet plan. This has not been done before implying the uniqueness and utmost applicability of the proposed technique [12].

Validation of the research is done by fuzzy technique for order of preference by similarity to ideal solution (TOPSIS). This involves expert doctors and hematologists who provide for the feedback required to validate the proposed work [13, 14]. The results obtained show the best diet among the available alternatives. It includes the meals that are to be taken three times a day in the form of breakfast, lunch and dinner. This shall comprehensively lay down a diet plan that a person must adhere to if he is suffering from anaemia. The main advantage of the proposed diet plan over the diets proposed by other methods in previous works is that a concrete diet plan is provided for which is made by keeping in consideration the nutrient demand of an individual by expert doctors and hematologists.

The organization of the paper is as follows. In section 2, the proposed methodology is discussed further, stating the background and the steps followed to obtain the results. In section 3, the experimental work is carried out using AHP and the results are obtained showing the best diet plan among the available ones. Further, in section 4, the validation of the work done in section 3 is carried out using Fuzzy TOPSIS. The results obtained in sections 3 and 4 are then compared and discussed in section 5. Finally, in section 6 , the conclusion is provided for and future scope of the proposed work has been discussed.

\section{Methodology used}

Multi criteria decision making (MCDM) approach is used in cases when the outcome depends upon the criteria and the impact of those criterions on the decision. AHP is a MCDM approach which was proposed and formulated by Thomas L. Saaty of in 1980. It is an extremely useful technique, one which involves both mathematical tools and psychological approach. It makes complex decision making an easy task by making pairwise comparisons of all the critical factors on the basis of priorities. It also makes pairwise comparisons of the alternatives on the basis of each factor. The Eigen values, Eigen vector, Consistency index and Consistency ratio help in determining the result. Consistency ratio with value less than 10 percent presents a consistent result. AHP employs the use of comparison matrices (Table 1). In order to perform the evaluation, Saaty proposed a fundamental scale of absolute numbers which is shown in the table below (Table 2). This scale provides for the numbers which can be used to present a comparison between criterions and the alternatives based on each criteria.

Application of AHP is advantageous as the diet recommendation becomes fairly easy to do as it incorporates all the critical nutrients in the proposed diet in most righteous way. Another advantage of AHP is that it checks the consistency of a Decision Maker's responses thus eliminating any biasness in the decision making process. For these advantages and the ability of AHP to help make precise decisions we have employed this technique in our paper.

Table 1. Sample comparison matrix

\begin{tabular}{|c|c|c|c|}
\hline $\mathbf{C}$ & $\mathbf{A}_{\mathbf{i}}$ & $\mathbf{A}_{\mathbf{j}}$ & $\mathbf{A}_{\mathbf{n}}$ \\
\hline $\mathbf{A}_{\mathbf{i}}$ & 1 & $\mathrm{a}_{\mathrm{ij}}$ & $\mathrm{a}_{\text {in }}$ \\
\hline $\mathbf{A}_{\mathbf{j}}$ & $1 / \mathrm{a}_{\mathrm{ij}}$ & 1 & $\mathrm{a}_{\text {jn }}$ \\
\hline $\mathbf{A}_{\mathbf{n}}$ & $1 / \mathrm{a}_{\mathrm{in}}$ & $1 / \mathrm{a}_{\mathrm{jn}}$ & 1 \\
\hline
\end{tabular}

Table 2. Scale proposed for evaluation

\begin{tabular}{|c|c|c|}
\hline $\begin{array}{c}\text { Importance } \\
\text { of factors }\end{array}$ & Meaning & Description \\
\hline 1 & $\begin{array}{l}\text { Equally } \\
\text { important }\end{array}$ & $\begin{array}{l}\text { Both factors are equally } \\
\text { important to each other }\end{array}$ \\
\hline 3 & $\begin{array}{l}\text { Slightly } \\
\text { important }\end{array}$ & $\begin{array}{c}\text { One factor is slightly } \\
\text { more important than the } \\
\text { other on the basis of } \\
\text { judgement }\end{array}$ \\
\hline 5 & $\begin{array}{l}\text { Highly } \\
\text { important }\end{array}$ & $\begin{array}{l}\text { One factor is more } \\
\text { important than other } \\
\text { factor by considerable } \\
\text { amount based on } \\
\text { judgement }\end{array}$ \\
\hline 7 & $\begin{array}{l}\text { Extremely } \\
\text { important }\end{array}$ & $\begin{array}{l}\text { One factor is really an } \\
\text { extremely important } \\
\text { over the other and this is } \\
\text { demonstrated in practice }\end{array}$ \\
\hline 9 & $\begin{array}{l}\text { Absolutely } \\
\text { important }\end{array}$ & $\begin{array}{c}\text { One factor has the } \\
\text { highest level of } \\
\text { importance as compared } \\
\text { to the other one }\end{array}$ \\
\hline $2,4,6,8$ & $\begin{array}{l}\text { Intermediate } \\
\text { values }\end{array}$ & $\begin{array}{l}\text { When neither adjacent } \\
\text { lower or upper values } \\
\text { given above are feasible }\end{array}$ \\
\hline
\end{tabular}


Table 3. Random consistency index table

\begin{tabular}{|c|c|c|c|c|c|c|}
\hline $\mathbf{n}$ & 1 & 2 & 3 & 4 & 5 & 6 \\
\hline C. I. & 0.0 & 0.0 & 0.58 & 0.90 & 1.12 & 1.24 \\
\hline
\end{tabular}

Table 4. Factors and their importance in the diet

\begin{tabular}{|c|c|}
\hline Factors & Importance of the factors in the diet \\
\hline Iron & $\begin{array}{l}\text { It is a critical part of the haemoglobin } \\
\text { which helps in carrying oxygen from the } \\
\text { lungs to the entire body by blood. It is } \\
\text { mainly found in the muscles and organs } \\
\text { such as liver of a person's body. Iron is } \\
\text { present in two forms: haem iron and non- } \\
\text { haem iron. Haem is mainly found in } \\
\text { animal products whereas non- haem iron } \\
\text { is found mainly in vegetables and pulses. } \\
\text { Our body must maintain the iron content } \\
\text { at a fixed level at all times. We lose iron } \\
\text { daily in the form of excretion, sweat, and } \\
\text { release of other bodily fluids. Women lose } \\
\text { the most amount of iron during their } \\
\text { periods, because a lot of blood is lost. }\end{array}$ \\
\hline Vitamin B12 & $\begin{array}{l}\text { It prevents pernicious anaemia by making } \\
\text { new red blood cells and also keeps nerve } \\
\text { cells healthy. It is necessary for protecting } \\
\text { one's body and inner linings of the tissue } \\
\text { from damage caused by the antibodies } \\
\text { present in the body. Its deficiency causes } \\
\text { destruction of inner lining of the stomach } \\
\text { which may have serious health } \\
\text { consequences. }\end{array}$ \\
\hline Vitamin C & $\begin{array}{l}\text { It helps in absorption of iron into the body } \\
\text { of the patient. More the amount of iron is } \\
\text { absorbed, more is the chance of early } \\
\text { recovery. }\end{array}$ \\
\hline Folic Acid & $\begin{array}{l}\text { It is a type of vitamin which helps in } \\
\text { making new cells in the body. Since the } \\
\text { body does not store much folic acid, it } \\
\text { must be provided for at regular interval to } \\
\text { promote sustained production of new } \\
\text { cells. }\end{array}$ \\
\hline
\end{tabular}

Steps for AHP are as follows:

Step 1: Find the critical factors.

Step 2: Determine the alternatives.

Step 3: Prepare a questionnaire and do a survey.

Step 4: Create pairwise comparison matrices using Saaty's fundamental scale.

Step 4: Calculate the $\mathrm{n}^{\text {th }}$ root of the product and their sum.

Step 5: Normalize the $\mathrm{n}^{\text {th }}$ root of the products determined and obtain the assigned weights.

Step 6: Determine the Consistency Index (C. I.) from the Saaty's random consistency index table (Table 3).

Step 7: Calculate and check Consistency Ratio (C. R.) which should be less than 0.10 or $10 \%$.
Step 8: Calculate the Reliability Index (R. I.) of the Alternatives

Step 9: Calculate the final rankings of the Alternatives.

\section{Experimental work}

\subsection{Determination of critical factors and diet alternatives}

The Diet plan of an Anaemia patient is based on a few critical factors. These factors were determined with the help of a survey conducted by us. Many renowned hematologists and Experts provided us with their responses. Essentially four factors/criterions were determined which are classified in the table shown below (Table 4).

Based on the above factors we are now presenting the alternative diet plans which were provided to us by renowned Doctors, who are considered experts in treatment of Anaemia and have vast experience in this field. These diet are prescribed keeping the above factors in mind. The nutritive value of the food is also kept in mind to provide the required amount of nutrient needed by a certain patient based upon the average intake of the nutrients.

Each diet plan consists of three essential meals of the day namely: Breakfast, Lunch and Dinner. The Diets are shown in the table given below (Table $5)$.

Table 5. Alternatives of diet and their components

\begin{tabular}{|c|l|}
\hline $\begin{array}{c}\text { Diet } \\
\text { alternatives }\end{array}$ & \multicolumn{1}{|c|}{ Components of the diet } \\
\hline Diet 1 (D1) & $\begin{array}{l}\text { Breakfast: White egg omelet made } \\
\text { with spinach, onion and tomato, milk }\end{array}$ \\
\cline { 2 - 2 } & $\begin{array}{l}\text { Lunch: Bajra roti, butter with dal and } \\
\text { lime }\end{array}$ \\
\cline { 2 - 3 } & $\begin{array}{l}\text { Dinner: Spinach soup, moong dal } \\
\text { khichdi, chapatti with ghee and lemon }\end{array}$ \\
\hline Diet 2 (D2) & Breakfast: Methi parantha with curd \\
\cline { 2 - 3 } & $\begin{array}{l}\text { Lunch: Dal and rice with mango } \\
\text { chutney }\end{array}$ \\
\cline { 2 - 2 } & $\begin{array}{l}\text { Dinner: Massor dal with chapatti and } \\
\text { dahi }\end{array}$ \\
\hline Diet 3 (D3) & $\begin{array}{l}\text { Breakfast: Orange juice with fortified } \\
\text { cereals in milk }\end{array}$ \\
\cline { 2 - 2 } & Lunch: Aloo palak, chapatti and salad \\
\cline { 2 - 2 } & $\begin{array}{l}\text { Dinner: Sem aloo with chapatti and } \\
\text { salad }\end{array}$ \\
\hline
\end{tabular}




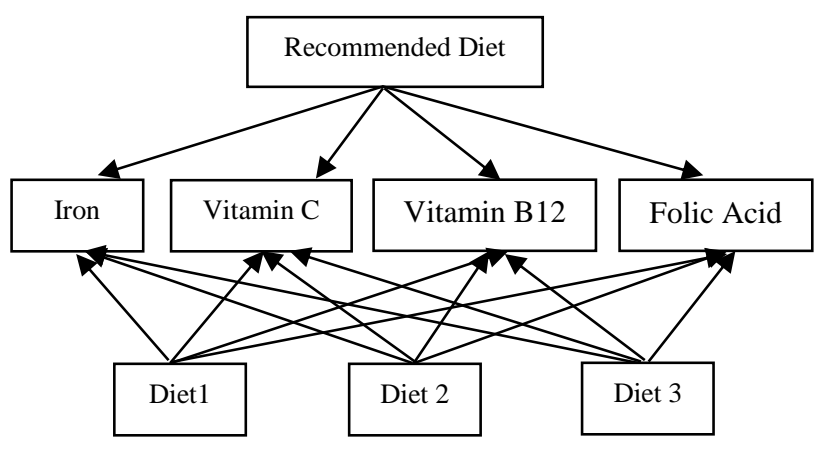

Figure.1 Proposed model

Table 6. Pairwise comparison matrix of criterions

\begin{tabular}{|c|c|c|c|c|c|}
\hline Criterions & F1 & F2 & F3 & F4 & $\begin{array}{c}\text { Eigen } \\
\text { Vector }\end{array}$ \\
\hline F1 & 1 & 3 & 5 & 7 & 0.563 \\
\hline F2 & 0.33 & 1 & 3 & 5 & 0.263 \\
\hline F3 & 0.20 & 0.33 & 1 & 3 & 0.117 \\
\hline F4 & 0.14 & 0.20 & 0.33 & 1 & 0.054 \\
\hline
\end{tabular}

Table 8. D1, D2 and D3 w.r.t F2

\begin{tabular}{|c|c|c|c|c|}
\hline & D1 & D2 & D3 & $\begin{array}{c}\text { Eigen } \\
\text { Vector }\end{array}$ \\
\hline D1 & 1 & 3 & 5 & 0.637 \\
\hline D2 & 0.33 & 1 & 3 & 0.258 \\
\hline D3 & 0.20 & 0.33 & 1 & 0.194 \\
\hline
\end{tabular}

Table 7. D1, D2 and D3 w.r.t F1

\begin{tabular}{|c|c|c|c|c|}
\hline & D1 & D2 & D3 & $\begin{array}{c}\text { Eigen } \\
\text { Vector }\end{array}$ \\
\hline D1 & 1 & 3 & 6 & 0.654 \\
\hline D2 & 0.33 & 1 & 3 & 0.249 \\
\hline D3 & 0.16 & 0.33 & 1 & 0.095 \\
\hline
\end{tabular}

Table 9. D1, D2 and D3 w.r.t F3

\begin{tabular}{|c|c|c|c|c|}
\hline & D1 & D2 & D3 & $\begin{array}{c}\text { Eigen } \\
\text { Vector }\end{array}$ \\
\hline D1 & 1 & 2 & 3 & 0.539 \\
\hline D2 & 0.50 & 1 & 2 & 0.297 \\
\hline D3 & 0.33 & 0.50 & 1 & 0.163 \\
\hline
\end{tabular}

\subsection{Model proposed for diet recommendation}

The proposed model for diet recommendation is shown above (Fig.1). It consists of three levels (from top to bottom):

Level 0: The recommended diet which is to be determined for an Anaemic Patient based on the data provided

Level 1: It contains the critical nutrients that must be a part of the diet.

Level 2: The alternative diet that are available to us are shown on this level.

\subsection{Calculation for criterions}

Here we calculate the different values of AHP which include Eigen Vectors, $\lambda_{\max }$, Consistency Index (C. I.) and Consistency ratio (C. R.) . The pairwise comparison of the criterions are shown in the table below (Table 6). The various factors are symbolized as: Iron (F1), Vitamin B12 (F2), Vitamin C (F3) and Folic Acid (F4). The calculated values are:

Mean $\lambda_{\max }=4.101$

C. I. $=0.033$, for $\mathrm{n}=4$.

C. R. $=.036<0.10$, Hence it is Consistent.

\subsection{Calculations for alternatives}

The calculations for alternative diet plans with respect to each factor defined above are shown. First, we calculate priorities of D1, D2 and D3 by pairwise comparison with respect to F1 using AHP (Table 7). For Table 7:

Eigen Vectors are $0.654,0.249$ and 0.095

Mean $\lambda_{\max }=3.018$

C. I. $=0.009$

C. R. $=0.015<0.10$, Hence Consistent.

Similarly, for D1, D2 and D3 with respect to F2, the values are calculated using AHP (Table 8).

Eigen Vector are 0.637, 0.258 and 0.194

Mean $\lambda_{\max }=3.039$

C. I. $=0.0195$

C. R. $=0.032<0.10$, Hence Consistent.

Similarly, for relative priorities of D1, D2 and D3 with respect to F3, the values are calculated (Table 9).

Eigen Vector are $0.539,0.297$ and 0.163

Mean $\lambda_{\max }=3.009$

C. I. $=0.0045$

C. $\mathrm{R} .=0.01<0.10$, Hence Consistent.

Similarly, for relative priorities of D1, D2 and D3 with respect to F4 by pairwise comparison using AHP, the values calculated are (Table 10):

Eigen Vector are $0.649,0.278$ and 0.071

Mean $\lambda_{\max }=3.065$

C. I. $=.0325$

C. $\mathrm{R} .=0.068<0.10$, Hence Consistent. 
Table 10. D1, D2 and D3 w.r.t F4

\begin{tabular}{|c|c|c|c|c|}
\hline & D1 & D2 & D3 & $\begin{array}{c}\text { Eigen } \\
\text { Vector }\end{array}$ \\
\hline D1 & 1 & 3 & 7 & 0.649 \\
\hline D2 & 0.33 & 1 & 5 & 0.278 \\
\hline D3 & 0.14 & 0.20 & 1 & 0.071 \\
\hline
\end{tabular}

Table 11. Reliability index for diet alternatives

\begin{tabular}{|c|c|c|}
\hline $\begin{array}{c}\text { Diet } \\
\text { Alternatives }\end{array}$ & Result & Ranking \\
\hline Diet 1 (D1) & $\mathbf{0 . 6 3 3}$ & $\mathbf{1}$ \\
\hline Diet 2 (D3) & 0.256 & 2 \\
\hline Diet 3 (D3) & 0.102 & 3 \\
\hline
\end{tabular}

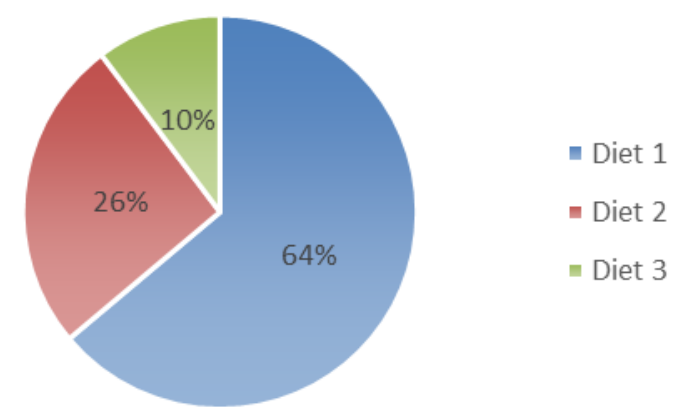

Figure.2 Pie- Chart for representation of weights of alternative diets

Table 12. Linguistic variables for relevance of criteria

\begin{tabular}{|c|c|}
\hline Very Low (VL) & $(0,0,0.1)$ \\
\hline Low (L) & $(0,0.1,0.3)$ \\
\hline Medium Low (ML) & $(0.1,0.3,0.5)$ \\
\hline Medium (M) & $(0.3,0.5,0.7)$ \\
\hline Medium High (MH) & $(0.5,0.7,0.9)$ \\
\hline High (H) & $(0.7,0.9,1.0)$ \\
\hline Very High (VH) & $(0.9,1.0,1.0)$ \\
\hline
\end{tabular}

Table 13. Linguistic variables to rate alternative diets

\begin{tabular}{|c|c|}
\hline Very Poor (VP) & $(0,0,1)$ \\
\hline Poor $(\mathrm{P})$ & $(0,1,3)$ \\
\hline Medium Poor $(\mathrm{MP})$ & $(1,3,5)$ \\
\hline Fair $(\mathrm{F})$ & $(3,5,7)$ \\
\hline Medium Good $(\mathrm{MG})$ & $(5,7,9)$ \\
\hline Good $(\mathrm{G})$ & $(7,9,10)$ \\
\hline Very Good $(\mathrm{VG})$ & $(9,10,10)$ \\
\hline
\end{tabular}

Now the reliability index for the diet alternatives is calculated by multiplying Eigen vectors obtained in tables $7,8,9,10$ by Eigen vectors obtained in table 6. The obtained results are shown below (Table 11) and illustrated with the help of a piechart (Fig.2).It clearly shows that Diet 1 is the most recommended diet for an anaemia patient.

The results obtained clearly show that diet plan 1 is the most suitable plan that needs to be adopted by an anaemia patient. The reliability index shows a whopping $63.3 \%$ weight in favor of the diet plan 1 . This diet has the best combination of critically essential nutrients, which are required by the patient to heal from anaemia.

\section{Validation of the work by fuzzy TOPSIS}

In order to address the linguistic and verbal uncertainties in the results obtained above, Fuzzy TOPSIS approach has been used here to validate the work done in section 3. This technique was proposed by $\mathrm{C}$. Cheng and Hwang [13]. The fundamental idea behind Fuzzy TOPSIS is that the resultant solution must be closest to positive ideal solution and should be farthest from negative solution. The final ranking of the alternatives is done on the basis of closeness coefficient which is the degree of closeness of an alternative to the positive ideal solution. Hence, higher the value of closeness coefficient, the higher is the rank of the alternative. This approach is better than conventional approaches for diet recommendation as in conventional approaches no concrete data is provided for to show the different meals that are to be consumed during the day. Only a vague idea about the type of diet has been proposed [7, 8, 9]. Fuzzy TOPSIS provides for eradication of that vagueness by strongly proposing for the different types of meal that can be consumed by the patient. This has been demonstrated in our work here. In order to understand the mechanism of this approach the steps for it are:

Step 1: Build an expert panel of Doctors who are distinguished experts in the field of medicine. We have included 3 distinguished Doctors in our committee.

Step 2: The evaluation criterions are identified as the same we used in AHP. These are Iron, Vitamin B12, Vitamin C and Folic Acid. The diet alternatives are also taken from our work done above as Diet 1, Diet 2 and Diet 3 .

Step 3: Now select from the linguistic variables (Table 12) to determine the importance of criterions developed followed by choosing the linguistic variables (Table 13) for determining the ratings of the available alternatives by the expert panel on the basis of criterions developed above [13].

Step 4: The importance weight of evaluation criterions (Table 14) and ratings of the alternatives (Table 15) is obtained by getting questionnaires filled by our decision makers (DM1, DM2 and DM3) using table 12 and table 13. 
Table 14. Linguistic variables for assessing importance of each criterion

\begin{tabular}{|c|c|c|c|}
\hline Factors & DM1 & DM2 & DM3 \\
\hline Iron (F1) & VH & H & H \\
\hline $\begin{array}{c}\text { Vitamin } \\
\text { B12 (F2) }\end{array}$ & MH & MH & MH \\
\hline $\begin{array}{c}\text { Vitamin C } \\
\text { (F3) }\end{array}$ & ML & ML & ML \\
\hline $\begin{array}{c}\text { Folic Acid } \\
\text { (F4) }\end{array}$ & L & ML & L \\
\hline
\end{tabular}

Table 15. Linguistic variables for assessing performance ratings of each alternative

\begin{tabular}{|c|c|c|c|c|}
\hline \multirow{2}{*}{ Factors } & $\begin{array}{c}\text { Diet } \\
\text { alternatives }\end{array}$ & DM1 & DM2 & DM3 \\
\hline \multirow{2}{*}{$\begin{array}{c}\text { Iron } \\
\text { (F1) }\end{array}$} & $\mathrm{D} 1$ & $\mathrm{G}$ & $\mathrm{G}$ & $\mathrm{VG}$ \\
\cline { 2 - 5 } & $\mathrm{D} 2$ & $\mathrm{MG}$ & $\mathrm{G}$ & $\mathrm{MG}$ \\
\cline { 2 - 5 } & $\mathrm{D} 3$ & $\mathrm{~F}$ & $\mathrm{~F}$ & $\mathrm{MG}$ \\
\hline Vitamin & $\mathrm{D} 1$ & $\mathrm{G}$ & $\mathrm{MG}$ & $\mathrm{G}$ \\
\cline { 2 - 5 } $\begin{array}{c}\text { B12 } \\
\text { (F2) }\end{array}$ & $\mathrm{D} 2$ & $\mathrm{~F}$ & $\mathrm{MG}$ & MG \\
\cline { 2 - 5 } Vitamin & $\mathrm{D} 3$ & $\mathrm{MP}$ & $\mathrm{F}$ & $\mathrm{F}$ \\
\cline { 2 - 5 } C (F3) & $\mathrm{D} 2$ & $\mathrm{G}$ & $\mathrm{MG}$ & MG \\
\cline { 2 - 5 } & $\mathrm{D} 3$ & $\mathrm{MP}$ & $\mathrm{F}$ & $\mathrm{F}$ \\
\hline \multirow{2}{*}{$\begin{array}{c}\text { Folic } \\
\text { Acid } \\
\text { (F4) }\end{array}$} & $\mathrm{D} 1$ & $\mathrm{MG}$ & $\mathrm{MG}$ & $\mathrm{F}$ \\
\cline { 2 - 5 } & $\mathrm{D} 2$ & $\mathrm{MP}$ & $\mathrm{F}$ & $\mathrm{F}$ \\
\hline
\end{tabular}

Table 16. Obtained fuzzy decision matrix

\begin{tabular}{|c|c|c|c|c|}
\hline D1 & 7.66, & 6.33, & 6.33, & 4.33, \\
& $9.33,10$ & 8.33, & 7.66, & 6.33, \\
& & 9.66 & 9.33 & 8.33 \\
\hline D2 & 5.66, & 4.33, & $3,5,7$ & 2.33, \\
& 7.66, & 6.33, & & 4.33, \\
& 9.33 & 8.33 & & 6.33 \\
\hline D3 & 3.66, & 2.33, & 0.33, & 0.67, \\
& 5.66, & 4.33, & 1.66, & 2.33, \\
& 7.66 & 6.33 & 3.66 & 4.33 \\
\hline Weights & 0.76, & 0.50, & 0.16, & 0.03, \\
& $0.93,1$ & 0.70, & 0.36, & 0.16, \\
& & 0.90 & 0.56 & 0.36 \\
\hline
\end{tabular}

Table 17. Obtained fuzzy normalized decision matrix

\begin{tabular}{|c|c|c|c|c|}
\hline & C1 & C2 & C3 & C4 \\
\hline D1 & 0.76, & 0.65, & 0.67, & 0.51, \\
& $0.93,1$ & $0.86,1$ & $0.82,1$ & $0.75,1$ \\
\hline D2 & 0.56, & 0.44, & 0.32, & 0.28, \\
& 0.76, & 0.65, & 0.53, & 0.51, \\
& 0.93 & 0.86 & 0.75 & 0.75 \\
\hline D3 & 0.36, & 0.24, & 0.03, & 0.08, \\
& 0.56, & 0.44, & 0.17, & 0.28, \\
& 0.76 & 0.65 & 0.39 & 0.51 \\
\hline
\end{tabular}

Step 5: Now calculate the fuzzy decision matrix and fuzzy weight of alternative diet plans from the tables obtained in step 4 (Table 16).

Step 6: In this step we calculate the fuzzy normalized decision matrix which is shown below (Table 17).

Step 7: In this step, the fuzzy weighted normalized decision matrix using equations given by C. T. Cheng is obtained. The fuzzy weighted normalized matrix is shown below (Table 18).

Step 8: Next, we move on to calculate the fuzzy positive ideal solution (FPIS) followed by fuzzy negative ideal solution (FNIS) which are given below.

$$
\begin{aligned}
& \mathrm{A}^{\tilde{*}^{*}}=[(1,1,1),(1,1,1),(1,1,1),(1,1,1)] \\
& \mathrm{A}^{\tilde{-}^{-}}=[(0,0,0),(0,0,0),(0,0,0),(0,0,0)]
\end{aligned}
$$

Step 9: Calculate the distance between each of the alternatives from FPIS and then calculate the distance of each alternative from FNIS as shown in table 19 and 20 below respectively.

Table 18. Fuzzy weighted normalized decision matrix

\begin{tabular}{|c|c|c|c|c|}
\hline $\begin{array}{c}\text { Diet } \\
\text { Plans }\end{array}$ & C1 & C2 & C3 & C4 \\
\hline D1 & 0.57, & 0.32, & 0.10, & $0.01,0.12$, \\
& 0.86, & 0.60, & 0.29, & 0.36 \\
& 1 & 0.90 & 0.56 & \\
\hline D2 & 0.42, & 0.22, & 0.05, & 0.008, \\
& 0.70, & 0.45, & 0.19, & $0.08,0.27$ \\
& 0.93 & 0.77 & 0.42 & \\
\hline D3 & 0.27, & 0.12, & 0.004, & 0.002, \\
& 0.52, & 0.30, & 0.06, & $0.004,0.18$ \\
& 0.76 & 0.58 & 0.21 & \\
& & & & \\
\hline
\end{tabular}

Table 19. Distance of each alternative from $\mathrm{A}^{*}$

\begin{tabular}{|c|c|}
\hline $\mathrm{d}_{1}{ }^{*}$ & 2.271 \\
\hline $\mathrm{d}_{2}{ }^{*}$ & 2.556 \\
\hline $\mathrm{d}_{3}{ }^{*}$ & 3.002 \\
\hline
\end{tabular}

Table 20. Distance of each alternative from $\mathrm{A}^{-}$

\begin{tabular}{|c|c|}
\hline $\mathrm{d}_{1}{ }^{-}$ & 2.063 \\
\hline $\mathrm{d}_{2}{ }^{-}$ & 1.674 \\
\hline $\mathrm{d}_{3}{ }^{-}$ & 1.168 \\
\hline
\end{tabular}


Table 21. Closeness coefficient and rank of alternatives

\begin{tabular}{|c|c|c|}
\hline $\begin{array}{c}\text { Diet } \\
\text { alternatives }\end{array}$ & $\begin{array}{c}\text { Closeness } \\
\text { coefficient }\end{array}$ & Rank \\
\hline D1 & $\mathbf{0 . 4 7 6}$ & $\mathbf{1}$ \\
\hline D2 & 0.396 & 2 \\
\hline D3 & 0.280 & 3 \\
\hline
\end{tabular}

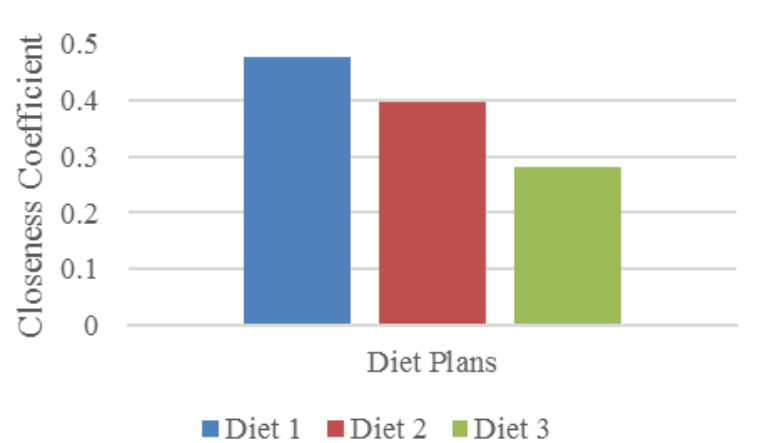

Figure. 3 Rank of alternatives obtained by fuzzy TOPSIS approach

Table 22. Comparison of the results obtained by AHP and fuzzy TOPSIS

\begin{tabular}{|c|c|c|c|c|}
\hline \multirow[t]{2}{*}{ Diets } & \multirow{2}{*}{$\begin{array}{c}\text { AHP } \\
\text { (reliability } \\
\text { index) }\end{array}$} & \multirow{2}{*}{$\begin{array}{c}\text { Fuzzy } \\
\text { TOPSIS } \\
\text { (closeness } \\
\text { coefficient) }\end{array}$} & \multicolumn{2}{|c|}{ Ranks } \\
\hline & & & AHP & $\begin{array}{c}\text { Fuzzy } \\
\text { TOPSIS }\end{array}$ \\
\hline D1 & 0.633 & 0.476 & 1 & 1 \\
\hline $\mathrm{D} 2$ & 0.256 & 0.396 & 2 & 2 \\
\hline D3 & 0.102 & 0.280 & 3 & 3 \\
\hline
\end{tabular}

Step 10: At the end calculate the closeness coefficient to know the rank of the alternative diet plans as shown below (Table 21). It is also represented in the chart shown below (Fig.3). The diet plan 1 has the highest value of closeness coefficient which means that it is nearest to the positive ideal solution and farthest from negative solution making it the best alternative. This shows the same result as obtained in section 3, Table 11 by AHP.

The results obtained above show clearly that diet 1 is the most recommended diet plan that must be administered to an anaemia patient. Fuzzy TOPSIS approach thus validates the results obtained in section 3 by AHP

\section{Results and discussions}

In section 3, AHP is used to determine the best diet plan among the three alternative diet plans provided by expert doctors. The results obtained by employing AHP shown in Table 11 and depicted in Fig. 2 pie chart show that the diet plan 1 is the most favored diet plan and it must be recommended to the patient suffering from anaemia. In order to validate our work, fuzzy TOPSIS was used in section 4. The findings of this method are depicted in Table 21 which shows the closeness coefficient and the ranking of the alternatives on its basis. Diet 1 has the highest value of closeness coefficient which means that it is the closest to positive ideal solution and farthest from negative ideal solution. Thus both the methods clearly signify that diet plan 1 is the recommended diet plan on the basis of nutrients that must be recommended to an anaemia patient. The comparison of the results is shown in the table below (Table 22).

\section{Conclusion}

Anaemia is seriously grappling our society. The deficiency of Iron coupled with malnutrition makes matter worse for those who have serious economic problems. Our paper has been made keeping the Indian perspective in mind. The diets that are mentioned have meals that are readily available in India. They are affordable and have high nutritional value. In conventional techniques of diet recommendation, the diets are not specifically mentioned rather a vague idea is provided for such as "Eat more protein rich foods". This causes confusion and ultimately provides no considerable benefit to the people. In order to remove this vagueness of diet plans and to provide more concrete results, AHP has been used to first determine the critical nutrients that must be present in the diet. These nutrients are prioritized on the basis of their importance to each other. On the basis of these nutrients alternative diet plans are recommended by expert doctors. These diet plans are then compared with respect to each other on the basis of the critical nutrients determined above. This provides for a more clear result which show the best diet plan among the available alternatives. In our case diet plan 1 was found to be the best among all.

The validation of the work is done by fuzzy TOPSIS so as to remove any linguistic errors and check for the consistency of the results obtained by AHP. The questionnaire for fuzzy TOPSIS is filled by three most experienced and seasoned doctors who have immense experience in the field of anaemia. The results obtained by this method also show similar trend as obtained by AHP. This lead to recommendation of the best diet plan which contains all the meals that must be consumed by an anaemia patient at breakfast, lunch and dinner.

The proposed paper contributes to the field of diet recommendation in many ways. Firstly, diet recommendation for anaemia has been done for the very first time by AHP and Fuzzy TOPSIS. This 
provides for explorations into this new and unchartered territory with a fresh point view which is away from the more conventional techniques of diet recommendation. Secondly, the diet plans consists of actual meals that are high in the nutrients required for curing anaemia. This is important as it shall enable future works to take inspiration from this point and provide for a more practical outcome than a theoretical idea. Thirdly, this technique can be used to find diet plans for many other diseases which require a patient to follow a high nutrition diet. Fourthly, this work could provide for a guidance system for doctors and other medical practitioners for recommending the diet plans to anaemic patients.

Future work can include determination of more diet alternatives and then trying to find out the best diet alternatives. The critical factors can be studied upon and other important nutrients can also be incorporated into the table such that the results become more appropriate. Another work that can be taken up is to merge the conventional techniques of diet recommendation with the approach proposed by us to provide for more scientifically accurate and better results. Factors such as age, gender, physical conditions, other diseases and much more factors can be used to provide for a more specific diet plan that caters to the needs of specific individual. Development of a web portal or a mobile based application can also be done by using the findings of our research work as well as the research work that shall be done in the future. This would provide for a more reliable way for imparting knowledge related to the diet plans a patient should follow to attain good health.

\section{References}

[1] http://www.firstpost.com/living/india-tops-thelist-of-nations-with-most-anaemic-women-andchildren-3075578.html, (accessed on 03.03.2017)

[2] http://data.worldbank.org/indiacator/SH.PRG.A NEM, (accessed on 05.03.2017)

[3] http://who.int/vmnis/anaemia/data/database/cou ntries/ind_ida.pdf?ua $=1, \quad$ (accessed on 13.03.2017)

[4] I. Ahmed, M. Alfonse, M. Aref, and A. Salem, "Daily meal planner expert system for diabetics type-2", E-Leader International Journal Prague, Vol. 10, No. 2, 2015.

[5] Y. Chi, T. Chen, and W. Tsai, "A chronic disease dietary consultation system using OWL-based ontologies and semantic rules",
Journal of Biomedical Informatics, Vol. 53, pp. 208- 219, 2015

[6] C. Lee, M. Wang, and H. Hagras, "A Type-2 Fuzzy Ontology and Its Application to Personal Diabetic-Diet Recommendation", IEEE Transactions on Fuzzy Systems, Vol 1, No. 2, pp. 374- 395, 2010.

[7] Y. Ting, Q. Zhao, and R. Chen, "Dietary Recommendation based on Recipe Ontology", In: Proc. of $6^{\text {th }}$ Conference on Awareness Science and Technology (iCAST), Paris, France, ISSN: 23255986, pp. 1- 6, 2014.

[8] A. Kale and N. Auti, "Automated Menu Planning Algorithm for Children: Food Recommendation by Dietary Management System using ID3 for Indian Food Database", Procedia Computer Science, Vol. 50, pp. 197202, 2015.

[9] S. Chavan and S. Sambare, "Study of Diet Recommendation System based on Fuzzy Logic and Ontology", International Journal of Computer Applications, Vol. 132, No. 12, pp. 20-24, 2015.

[10] G. Kovasznai, "Developing an Expert System for Diet Recommendation", In: Proc. of $6^{\text {th }}$ IEEE Symposium on Applied Computational Intelligence and Informatics, Timisoara, Romania, pp. 505- 509, 2011.

[11] W. Husain, L. Wei, S. Cheng, and N. Zakaria, "Application of Data Mining Techniques in a Personalized Diet Recommendation System for Cancer Patients", IEEE Colloquium on Humanities Science and Engineering Research, pp. 239-244, 2011.

[12] T. Saaty, "The Analytic Hierarchy Process: Planning, Priority Setting, Resource Allocation", Mcgraw- Hill, Texas, 1980.

[13] C. Chen, "Extensions of the TOPSIS for group decision-making under fuzzy environment", Fuzzy Sets and Systems, Vol. 114, No. 1, pp. 19, 2000.

[14] C. Sharma and S. Dubey, "Reliability Evaluation of Software System Using AHP and Fuzzy TOPSIS Approach", In: Proc. of the Fifth International Conference on Soft Computing for Problem Solving, Springer, Vol. 437, pp. 81- 92, 2016. 